\title{
ESTERILIZAÇÃO DE SOROS E VACINAS POR RADIAÇÃO GAMA DE COBALTO*
}

\author{
Rosalvo Guidolin** \\ Alcino Corrêa*** \\ Regina Maria Barreto Cicarelli**** \\ Eloi Previde***** \\ Josefina Farina Morais** \\ Hisako Gondo Higashi**
}

\begin{abstract}
GUIDOLIN, R. et al. Esterilização de soros e vacinas por radiação gama de cobalto. Rev. Saúde públ., S. Paulo, 22:113-7, 1988.

RESUMO: Os soros antitetânico, antidiftérico e antibotrópico-crotálico e, ainda, a vacina diftérica-pertussis-tetânica foram submetidos a diferentes intensidades de radiação gama, com os seguintes intuitos: verificação da resistência das atividades específicas destes produtos à ação dos raios gama; avaliação das possibilidades de utilização deste tipo de energia radiante para a esterilização de alguns soros hiperimunes heterólogos e vacinas, mais comumente utilizados em saúde pública. Os resultados obtidos, segundo os parâmetros empregados, mostraram a possibiildade de esterilização sem alteraçốes das atividades específicas, de ordem biológica ou química, dos produtos experimentados.
\end{abstract}

UNITERMOS: Esterilização, métodos. Raios gama. Toxóide tetânico, efeitos de radiação. Toxóide diftérico, efeitos de radiação. Vacina pertussis, efeitos de radiação. Antitoxina tetânica, efeitos de radiação. Antitoxina diftérica, efeitos de radiação. Antivenenos, efeitos de radiação.

\section{INTRODUÇÃO}

A energia radiante para esterilizações vem sendo aplicada com sucesso nestes últimos anos. Produtos alimentícios ${ }^{10-13,16,19,21}$, cosméti$\cos ^{9}$, materiais cirúrgicos descartáveis ${ }^{2}$, vacinas, soros e produtos do sangue ${ }^{1} \mathrm{e}$ outros ${ }^{3-7,17,19,20,22}$, são descontaminados por radiações.

A energia eletromagnética derivada de cobalto é a que se utiliza com maior frequiência na esterilização dos materiais mencionados. Este tipo de energia, como a radiação gama, não aquece o produto, podendo, assim, ser também aplicada a produtos biológicos que, na maioria das vezes, são susceptíveis a temperaturas relativamente elevadas.

A esterilização de soros terapêuticos e de algumas vacinas não adicionadas de adjuvantes particulados é feita geralmente pela filtração. $\mathrm{Na}$ dependência do tipo de produto e dos filtros esterilizantes usados, o processo é relativamente demorado e, invariavelmente, ocor- rem perdas de volumes que são, às vezes, consideráveis. Devido a falhas humanas ou outras causas, após a filtração observam-se contaminações relativamente frequientes que, ou condenam o produto definitivamente ou, pelo menos, obrigam a uma nova filtração e, conseqüentemente, aumenta a perda em volume. Tratando-se de vacinas adicionadas de adjuvantes particulados, todo o trabalho é executado sob condições estéreis. Neste caso, quando ocorre contaminação, o produto não tem condições de ser recuperado.

A radiação gama, devido ao seu elevado poder de penetração, esteriliza os produtos após o envasamento e, inclusive, após ter sido acondicionado em embalagens habituais.

A bibliografia compulsada não trazia informações suficientes quanto a utilização deste tipo de energia na esterilização de produto de natureza biológica, tais como soros hiperimunes ou vacinas. Não havia, praticamente, dúvidas quanto à ação dos raios gama esterilizantes, mas sim quanto a redução de ati-

* Apresentado no IX Congresso Latino-Americano de Microbiologia e XII Congresso Brasileiro de Microbiologia. São Paulo, julho de 1983.

** Instituto Butantan - Av. Vital Brasil, 1500 - 05503 - São Paulo, SP — Brasil.

*** Syntex do Brasil - Rua Maria Cândida, 1817 - São Paulo, SP — Brasil.

**** Faculdade de Farmácia e Odontologia de Araraquara - Rua Expedicionários do Brasil, 1621 14800 - Araraquara, SP - Brasil.

***** IBRAS - CBO. Indústrias Cirúrgicas e ópticas S.A. - Campinas, SP - Brasil. 
vidade biológica, por destruição de princípios ativos destes produtos.

Resolvemos, assim, observar o comportamento dos soros antitetânico, antidifetérico e antiofídico e da vacina tríplice (tétano-difteria-pertussis precipitada pelo alúmen), frente a diferentes intensidades de radiação gama.

\section{MATERIAL E METODOS}

As experiências foram iniciadas em 1981 com produtos que eram normalmente preparados pela Syntex do Brasil, Indústria e Comércio Ltda. As aplicações de energia radiante eram efetuadas com 0 equipamento industrial da IBRAS-CBO, Indústrias Cirúrgicas e Opticas S.A., de Campinas, SP.

\section{Soros Hiperimunes}

Os soros utilizados foram obtidos de plasmas de cavalos hiperimunizados. Os plasmas foram purificados e concentrados por digestão péptica ${ }^{14}$ e sob controles biológicos e químicos de acordo com as especificações da Farmacopéia Brasileira, 2. ${ }^{a}$ ed. ${ }^{6}$. Utilizamos os soros antidiftérico (SAD), antitetânico (SAT), antiofídico (SAO) - que é a associação do antibotrópico e anticrotálico no total de 14 amostras.

\section{Vacinas}

Foi utilizada uma amostra de vacina "Tríplice" (DTP) que consiste de uma associação de vacina tetânica, diftérica e suspensão de Bordetella pertussis, controlada química e biologicamente de acordo com as especificações dos "Requisitos Mínimos da Organização Mundial de Saúde"15.

\section{Tratamentos Esterilizantes Aplicados}

As experiências foram distribuídas em dois grupos:

\section{Grupo I}

Amostras de 10 partidas de SAT foram esterilizadas por filtração em placas $E \mathrm{KS}_{2} \mathrm{e}$, em seguida, a metade do volume de cada amostra foi distribuída em ampolas, com $10 \mathrm{ml}$, mantendo-se estéril ${ }^{8}$. A outra metade foi propositadamente contaminada com cultura esporulada de Bacillus subtilis e distribuída em ampolas, com $10 \mathrm{ml}$.

As provas de esterilidade ${ }^{8}$ destas ampolas revelaram abundante desenvolvimento bacteriano 24 horas após a semeadura, em estufa a $37^{\circ} \mathrm{C}$. Foi encontrado, ao exame morfológico, apenas bacilos com as características do $B$. subtilis.

\section{Grupo II}

Foram utilizados, neste grupo: SAD, SAT, SAO e DPT. Todos os produtos foram preparados pelo método de rotina e os soros foram previamente esterilizados por filtração.

\section{Doses de Irradiação (DI)}

As DI variaram de 0,40 a $2,55 \mathrm{mrad}$. A irradiação, nas doses mencionadas, foi aplicada em 5 conjuntos individuais de 50 ampolas. As ampolas estavam embaladas em caixas de cartolina, com 5 em cada caixa.

\section{Período de Observação}

Uma amostra de cada um dos produtos foi analisada durante um periodo de 18 meses, após a irradiação, quanto ao título antitóxico, concentração de fenol e esterilidade. No que diz respeito ao $\mathrm{pH}$, concentração protéica, concentração de cloreto de sódio e pirogênio, os testes feitos trimestralmente demonstraram estarem de acordo com as determinações de Farmacopéia Brasileira. ${ }^{8}$

\section{RESULTADOS}

Os resultados obtidos nos testes com o grupo I, imediatamente após irradiação, estão reunidos na Tabela 1 .

\section{TABELA 1}

Doseamento de amostras de SAT propositadamente contaminadas com cultura esporulada de $B$. subtilis*

\begin{tabular}{cccccc}
\hline & & \multicolumn{3}{c}{$\begin{array}{c}\text { Atividade Neutra- } \\
\text { zante }\end{array}$} & \multicolumn{2}{c}{ Esterilidade } \\
$\begin{array}{c}\text { Amostras } \\
\text { n. }\end{array}$ & $\begin{array}{c}\text { DI } \\
\text { Mrad }\end{array}$ & \multicolumn{2}{c}{ U.I/ml } & & \\
\cline { 3 - 6 } & & $\begin{array}{c}\text { Antes } \\
\text { DI }\end{array}$ & $\begin{array}{c}\text { Após } \\
\text { DI }\end{array}$ & $\begin{array}{c}\text { Antes } \\
\text { DI }\end{array}$ & $\begin{array}{c}\text { Após } \\
\text { DI }\end{array}$ \\
\hline 1 & 0,40 & 190 & 190 & C & C \\
2 & 0,45 & 190 & 190 & C & C \\
3 & 0,50 & 190 & 190 & C & C \\
4 & 0,55 & 190 & 190 & C & C \\
5 & 0,60 & 190 & 190 & C & C \\
$8-120$ & 1,25 & 190 & 190 & C & E \\
$10-160$ & 1,55 & 190 & 190 & C & E \\
$9-170$ & 1,65 & 190 & 190 & C & E \\
$7-215$ & 2,00 & 190 & 125 & C & E \\
$6-280$ & 2,55 & 190 & 100 & C & E \\
\hline
\end{tabular}

SAT $=$ Soro antitetânico

DI = Dose irradiante em mrad

C $=$ contaminado

$\mathrm{E}=$ estéril

* Concentrações de Fenol, $\mathrm{NaCl}$ e protéica, pH, pirogênio e viscosidade - dentro dos limites estabelecidos pela Farmacopéia Brasileira ${ }^{8}$. 
Um mês após a irradiação, os testes de estabilidade quanto ao título antitóxico, de concentração de fenol e de esterilidade, foram repetidos com as amostras 8-120 e 10-160. Foram assim escolhidas porque a dose de irradiação de 1,25 e $1,55 \mathrm{mrad}$ representavam, pela nossa experiência até então, a mínima esterilizante $(1,25)$ e a máxima tolerada, com ótima margem de segurança $(1,55)$. Os resultados estão contidos na Tabela 2.

Em vista dos resultados iniciais satisfatórios observados com o SAT de 190 U.I./ml, resolvemos ampliar as nossas observações, aplicando o mesmo método de esterilização aos seguintes produtos: SAT, SAD e SAO, com concentrações mais elevadas de imunoglobulinas específicas e, ainda, com a vacina DPT, com a qual não tínhamos nenhuma experiência.

Os produtos foram analisados entre $12 \mathrm{e}$ 18 meses após, e os resultados destas provas estão demonstrados na Tabela 3 que compara o mesmo produto esterilizado pelo método convencional de filtração e por irradiação gama, respectivamente.

Todos os soros relacionados apresentaramse estéreis e sem alteração no que diz respeito a concentração de fenol durante os períodos de observações.

A Tabela 4 resume os resultados obtidos com a irradiação da DPT $(1,4 \mathrm{mrad})$ comparados com os resultados de parte da mesma vacina não irradiada.

\section{DISCUSSĀO}

A radiação ionizante vem sendo aplicada há alguns anos na prática de esterilização de diferentes produtos de consumo humano e animal. No entanto, pairavam algumas dúvidas quanto ao seu efeito adverso em certos produtos biológicos, como o soro antitetânico ${ }^{1}$, cuja atividade seria destruída em parte por este tipo de energia. Com a técnica por nós empregada, dentro dos limites estabelecidos (1,65 mrad), não foi verificada perda de atividade neste tipo de soro. Diversas partidas de soros irradiadas até 1,8 mrad não apresentaram qualquer alteração nas propriedades físico-químicas e biológicas.

O nível de segurança oferecido pela aplicação de raios gama como agente esterilizante é bem maior do que aquele derivado das téc-

TABELA 2

Doseamento de amostras de SAT (atividade, concentração de fenol e esterilidade)

\begin{tabular}{|c|c|c|c|c|c|c|c|}
\hline \multirow{2}{*}{$\begin{array}{c}\text { Amostras } \\
\mathbf{n} .^{\circ}\end{array}$} & \multirow{2}{*}{$\underset{\operatorname{mrad}}{\mathrm{DI}}$} & \multirow{2}{*}{ 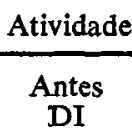 } & \multirow{2}{*}{ 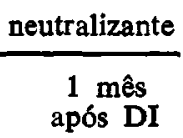 } & \multicolumn{2}{|c|}{ Concentração fenol $\mathrm{g} \%$} & \multicolumn{2}{|c|}{ Esterilidade } \\
\hline & & & & $\begin{array}{c}\text { Antes } \\
\text { DI }\end{array}$ & $\begin{array}{l}1 \text { mês } \\
\text { após DI }\end{array}$ & $\begin{array}{l}\text { Antes } \\
\text { DI }\end{array}$ & $\begin{array}{c}1 \text { mes } \\
\text { após DI }\end{array}$ \\
\hline $8-120$ & 1,25 & 190 & 190 & 0,39 & 0,39 & $\mathrm{C}$ & $\mathbf{E}$ \\
\hline $10-160$ & 1,55 & 190 & 190 & 0,39 & 0,38 & C & $\mathbf{E}$ \\
\hline
\end{tabular}

SAT = Soro antitetânico

DI - Dose de Irradiação em mrad

C - Contaminado

E - Estéril

TABELA 3

Doseamento comparativo entre SAD, SAT e SAO, esterilizados e por irradiação gama $(1,4 \mathrm{mrad})$

\begin{tabular}{|c|c|c|c|c|c|c|c|c|c|}
\hline \multirow{2}{*}{\multicolumn{2}{|c|}{ Produto }} & \multicolumn{2}{|c|}{ Inicial } & \multicolumn{2}{|c|}{1 mês } & \multicolumn{2}{|c|}{12 meses } & \multicolumn{2}{|c|}{18 meses } \\
\hline & & $\begin{array}{c}\text { Filtra- } \\
\text { da }\end{array}$ & $\begin{array}{l}\text { Irra- } \\
\text { diada }\end{array}$ & $\begin{array}{c}\text { Filtra- } \\
\text { da }\end{array}$ & $\begin{array}{l}\text { Irra- } \\
\text { diada }\end{array}$ & $\begin{array}{c}\text { Filtra- } \\
\text { da }\end{array}$ & $\begin{array}{l}\text { Irra- } \\
\text { diada }\end{array}$ & $\begin{array}{c}\text { Filtra- } \\
\mathrm{da}\end{array}$ & $\begin{array}{l}\text { Irra- } \\
\text { diada }\end{array}$ \\
\hline \multirow{2}{*}{\multicolumn{2}{|c|}{$\begin{array}{l}\text { SAD } \\
\text { SAT }\end{array}$}} & 1,250 & 1,250 & 1,250 & 1,250 & 1,200 & 1,250 & 1,200 & 1,250 \\
\hline & & 2,900 & 2,900 & 2,900 & 2,900 & 2,900 & 2,900 & - & 2,900 \\
\hline \multirow{2}{*}{ SAO } & Botrópico & 2,05 & 2,05 & 2,05 & 2,05 & - & 2,05 & - & - \\
\hline & Crotálico & 1,23 & 1,23 & 1,30 & 1,30 & - & 1,25 & - & - \\
\hline
\end{tabular}

$\mathrm{SAD}$ (soro antidiftérico) $=\mathrm{UI} / \mathrm{ml}$

SAT (soro antitetânico) $=\mathrm{UI} / \mathrm{ml}$

SAO (soro antiofídico) $=\mathrm{mg} / \mathrm{ml}$ 
TABELA 4

Doseamento comparativo entre as vacinas DPT não irradiada e irradiada*

\begin{tabular}{|c|c|c|c|c|c|c|}
\hline \multirow{3}{*}{$\begin{array}{l}\text { Períodos de } \\
\text { observação }\end{array}$} & \multicolumn{6}{|c|}{ Unidades internacionais por $\mathrm{ml}$} \\
\hline & \multicolumn{3}{|c|}{ Não irradiada } & \multicolumn{3}{|c|}{ Irradiada** } \\
\hline & $\mathrm{D}$ & $\mathbf{P}$ & $\mathbf{T}$ & $\mathrm{D}$ & $\mathbf{P}$ & $\mathrm{T}$ \\
\hline Inicial ** & 3,0 & 5,25 & 4,0 & 4,0 & 5,63 & 4,0 \\
\hline Após 12 meses & 3,0 & 4,30 & 3,0 & 4,0 & 4,30 & 3,0 \\
\hline
\end{tabular}

DPT = Vacina tríplice (difteria, suspensão de Bordetella pertussis e tétano).

* Ambas apresentaram-se estéreis durante os períodos de observação.

* Imediatamente após a preparação da vacina.

nicas de filtrações, habitualmente empregadas para a finalidade e especialmente desejadas, quando se trata da esterilização de produtos derivados do sangue de animais e de humanos. Vírus e micoplasmas, estes em certos estágios do seu desenvolvimento, passam através de membranas inertes ou placas de filtros esterilizantes de profundidade. $\mathrm{Na}$ produção em escala industrial de vacinas virais, em cultivos celulares, é relativamente freqüente a constatação de contaminações do soro normal utilizado por vírus estranhos e, especialmente, por micoplasmas. Esses agentes contaminantes são susceptíveis à destruição pela ação dos raios gama.

Face ao poder penetrante deste tipo de radiação, os produtos podem ser esterilizados após o envasamento e mesmo após a embalagem, eliminando assim os riscos de contaminações durante o processo de ampolamento. Segundo determinação da Farmacopéia Brasileira ${ }^{8}$ a amostragem para as provas de esterilidade de soros e vacinas é feita segundo a fórmula $0,4 \sqrt{n}$, onde " $n$ " corresponde ao número de ampolas envasadas por lote de fabricação. Esta amostragem não exclui totalmente a eventualidade de liberação de algumas ampolas contaminadas durante o envasamento. Estas possibilidades aumentam quando o produto é liofilizado, cujo processo de secagem é, obviamente, feito com ampolas ou frascos abertos.

Por outro lado, algumas desvantagens da esterilização por raios gama devem ser mencionadas:

- custo elevado do equipamento emissor de raios gama;

- necessidade imediata de irradiação do produto para evitar o desenvolvimento de microrganismos contaminantes;

- escurecimento do material de vidro (ampolas, frascos) pela ação dos raios gama;

— riscos de mutações genéticas de microrganismos submetidos a doses subletais de energia radiante.

GUIDOLIN, R. et al. (Sterilization of sera and vaccines by cobalt gamma radiation]. Rev. Saúde públ., S. Paulo, 22:113-7, 1988.

ABSTRACT: Diphteria, tetanus, anti-snake venom sera and Diphteria-Pertussis-Tetanus vaccine were submited to different intensities of gamma radiation, in order to: verify the resistance of their specific activities to the action of gamma rays; evaluate the possibility of using this type of energy to sterilize some heterogenous hyperimmune sera and vaccines commonly utilized in Public Health. The results, according to the range employed, show the possibility of sterilizing the products tested, without any alteration to specific biological and chemical properties.

UNITERMS: Sterilization, methods. Gamma rays. Tetanus toxoid, radiation effects. Diphteria toxoid, radiation effects. Pertussis vaccine, radiation effects. Tetanus antitoxin, radiation effects. Diphteria antitoxin, radiation effects. Antivenin, radiation effects. 


\section{REFERENCIAS BIBLIOGRĀFICAS}

1. BANKER, D. D. Radiation sterilization of vaccines, antesera and blood products. In: National Workshop on Radiation Sterilization of Biomedical Products and Pharmaceuticals, Bhabha Atomic Research Center Trombay, Bombay, 1982. Proceedings. Bombay, 1982. p. 10-7.

2. BAVADEKAR, A. V. Practical applications of radiation sterilized products in clinical practice. In: National Workshop on Radiation Sterilization of Biomedical Products and Pharmaceuticals, Bhabha Atomic Research Center Trombay, Bombay, 1982. Proceedings. Bombay, 1982. p. 1-9.

3. BHIRUD, S. D. Drugs control aspects of radiation sterilization of medical products and pharmaceuticals. In: National Workshop on Radiation Sterilization of Biomedical Products and Pharmaceuticals, Bhabha Atomic Research Center Trombay, Bombay, 1982. Proceedings. Bombay, 1982. p. 77-92.

4. BOGOKOWSKY, B. \& ALTMANN, G. Bacterial giowth on Mueller Hinton Medium Sterilized by gamma Radiation. Int. J. appl. Radiat. Isot., 32:891-3, 1981.

5. BOGOKOWSKY, B.; EISENBERG, E.; ALTMANN, G. Sterilization of McConkey Agar and Cled Medium by gamma Radiation. Int. J. appl. Radiat. Isot., 34:441-3, 1983.

6. BRODOROTTI, H. S. von \& MAHNEL, $H$. Inactivation of viruses and bacteria in sewage sludge by gamma radiation. Zentralbl. Bakteriol. Mikrobiol. Hyg. B, 170:71-81, 1980.

7. DAWSON, J. O. Different methods of sterilization of medical products. In: Symposium on Radiosterilization of Medical Products, Bombay, 1974. Proceedings. Bombay, 1974. .p 265-7.

8. FARMACOPELA dos Estados Unidos do Brasil. 2. ${ }^{2}$ ed. São Paulo, Indústria Gráfica Siqueira S.A., 1959. p. 1027-35.

9. GOPAL, N. G. S. Application of radiation in sterilization of pharmaceuticals: cosmetics and toiletry. In: National Workshop on Radiation Sterilization of Biomedical Prcducts and Pharmaceuticals, Bhabha Atomic Research Center Trombay, Bombay, 1982. Proceedings. Bombay, 1982. p. 63-72.

10. ITO, H.; WATANABE, H.; BAGIAWATI, S.; MUHAMAD, L. J.; TAMURA, N. Distribution of microrganisms in specie and their descontamination by gamma irradiation. In: Symposium on Food Irradiation Processing, Washington, D. C., 1985. Proceedings. Vienna, I.A.E.A., 1985. p. 171.

11. KALMAN, B. \& KEKESSI, E. Introduction of irradiation technology into the Hungarian food industry. In: Symposium on Food Irradiation Processing, Washington, D. C., 1985. Proceedings. Vienna, I.A.E.A., 1985. p. 109-15.

12 KAMPELMACHER, E. H. Prospects of eliminating pathogens by the process of food irra- diation, combination processes. In: Symposium on Food Irradiation, Colombo, 1980. Proceedings. Vienna, I.A.E.A., 1981. p. 265-85.

13. MANOTO, E. C.; BLANCO, L. R.; MENDOZA, A. B.; RESILVA, S. S. Disinfestation of Copra, desiccated coconut and coffee beans by gamma radiation. In: Syposium on Food Irradiation Processing, Washington, D. C., 1985. Proceedings. Vienna, I.A.E.A., 1985. p. 169.

14. ORGANIZACIÓN PANAMERICANA DE LA SALUD. Manual de procedimentos: producción y pruebas de control in la preparación de antisueros difterico, tetanico, botulinico, antivenenos y de la gangrena gaseosa. Washington, D. C., 1977.

15. WORLD HEALTH ORGANIZATION. Manual for the production and control of vaccines. Geneva, 1977. (BLG/UNDP/77.2).

16. MOY, J. H.; OHTA, A. T.; KANESHIRO K. Y.; NAGAI, N. Y. Disinfestation of Medfly in oranges by combining gamma $\mathrm{Ra}$ diation and cold treatments. In: Symposium on Food Irradiation Processing, Washington, D. C., 1985. Proceedings. Vienna, I.A.E.A., 1985. p. 168.

17. PATIL, K. M. Microbiological aspects of radiation sterilization. In: National Workshop on Radiation Sterilization of Biomedical Products and Pharmaceuticals, Bhabha Atomic Research Center Trombay, Bombay, 1982. Proceedings. Bombay, 1982. p. 45-56.

18. SEKHAVAT, A.; ZARE, Z.; KUDVA, M. G.; CHOPRA, K. L.; SHARIAT PANAHI, J. M. Preservation of potatoes and onions by irradiation and chemical treatments. In: Symposium on Food Preservation by Irradiation, Viageningen, 1977. Proceedings. Vienna, I.A.E.A., 1978. p. 83-97.

19. SOEMARTAPUTRA, M. H.; HARYADI, R. S. RAHAYU, A.; KARDHA, S.; PURWANTO, Z. I.; CHOSDU, R. Radiation disinfestation of tabacco Balis and coffee Beans. In: Symposium on Food Irradiation Processing, Washington, D. C., 1985. Proceedings. Vienna, I.A.E.A., 1985. p. 170.

20. SOBDWA, N. N.; IVANOVA, I.; TALRONE V. L.; TROFIMOV, V. I.; FEDOTOV, V. P. Radiation resistivity of frozen insulin solution and suspensions. Int. J. appl. Radiat. Isot., 32: $753-6,1981$.

21. RIGNEY, G. J.; SUDATIS, B.; IZARD, M. Irradiation disinfestation of apples. In: Symposium on Food Irradiation Processing, Washington, D. C., 1985. Proceedings. Vienna, I.A.E.A., 1985. p. 169.

22. TIMMERMAN, R. Irradiated plastics products. Engineer's Report. [Fotocópia].

Recebido para publicação em: 5/6/1987 Reapresentado em: 9/11/1987

Aprovado para publicação em: 10/11/1987 